\title{
CHARACTERIZATION OF CONDITIONS OF NATURAL GAS STORAGE RESERVOIRS AND DESIGN AND DEMONSTRATION OF REMEDIAL TECHNIQUES FOR DAMAGE MECHANISMS FOUND THEREIN
}

\section{ANNUAL TECHNICAL PROGRESS REPORT}

1 OCTOBER 2001 - 30 SEPTEMBER 2002

\author{
J. H. Frantz, Jr., Project Director \\ K. G. Brown, Principle Investigator
}

February 2003

DE-FG26-99FT40703

Schlumberger

Data and Consulting Services

1310 Commerce Drive

Park Ridge 1

Pittsburgh, PA 15275-1011 


\section{DISCLAIMER}

This report was prepared as an account of work sponsored by an agency of the United States Government. Neither the United States Government nor any agency thereof, nor any of their employees, makes any warranty, express or implied, or assumes any legal liability or responsibility for the accuracy, completeness, or usefulness of any information, apparatus, product, or process disclosed, or represents that its use would not infringe privately owned rights. Reference herein to any specific commercial product, process, or service by trade name, trademark, manufacturer, or otherwise does not necessarily constitute or imply its endorsement, recommendation, or favoring by the United States Government or any agency thereof. The views and opinions of authors expressed herein do not necessarily state or reflect those of the Unites States Government or any agency thereof. 


\section{ABSTRACT}

There are four primary goals of contract DE-FG26-99FT40703:

1) We seek to better understand how and why a specific iron-related inorganic precipitant, siderite, occurs at the reservoir/wellbore interface in gas storage wells.

2) We plan on testing potential prevention and remediation strategies related to this damage mechanism in the laboratory.

3) We expect to demonstrate in the field, cost-effective prevention and remediation strategies that laboratory testing deems viable.

4) We will investigate new technology for the gas storage industry that will provide operators with a cost effective method to reduce non-darcy turbulent flow effects on flow rate.

For the above damage mechanism, our research efforts will demonstrate the diagnostic technique for determining the damage mechanisms associated with lost deliverability as well as demonstrate and evaluate the remedial techniques in the laboratory setting and in actual gas storage reservoirs.

We plan on accomplishing the above goals by performing extensive lab analyses of rotary sidewall cores taken from at least two wells, testing potential remediation strategies in the lab, and demonstrating in the field the applicability of the proposed remediation treatments.

The benefits from this work will be quantified from this study and extrapolated to the entire storage industry. The technology and project results will be transferred to the industry through DOE dissemination and through the industry service companies that work on gas storage wells.

Achieving these goals will enable the underground gas storage industry to more costeffectively mitigate declining deliverability in their storage fields. 


\section{TABLE OF CONTENTS}

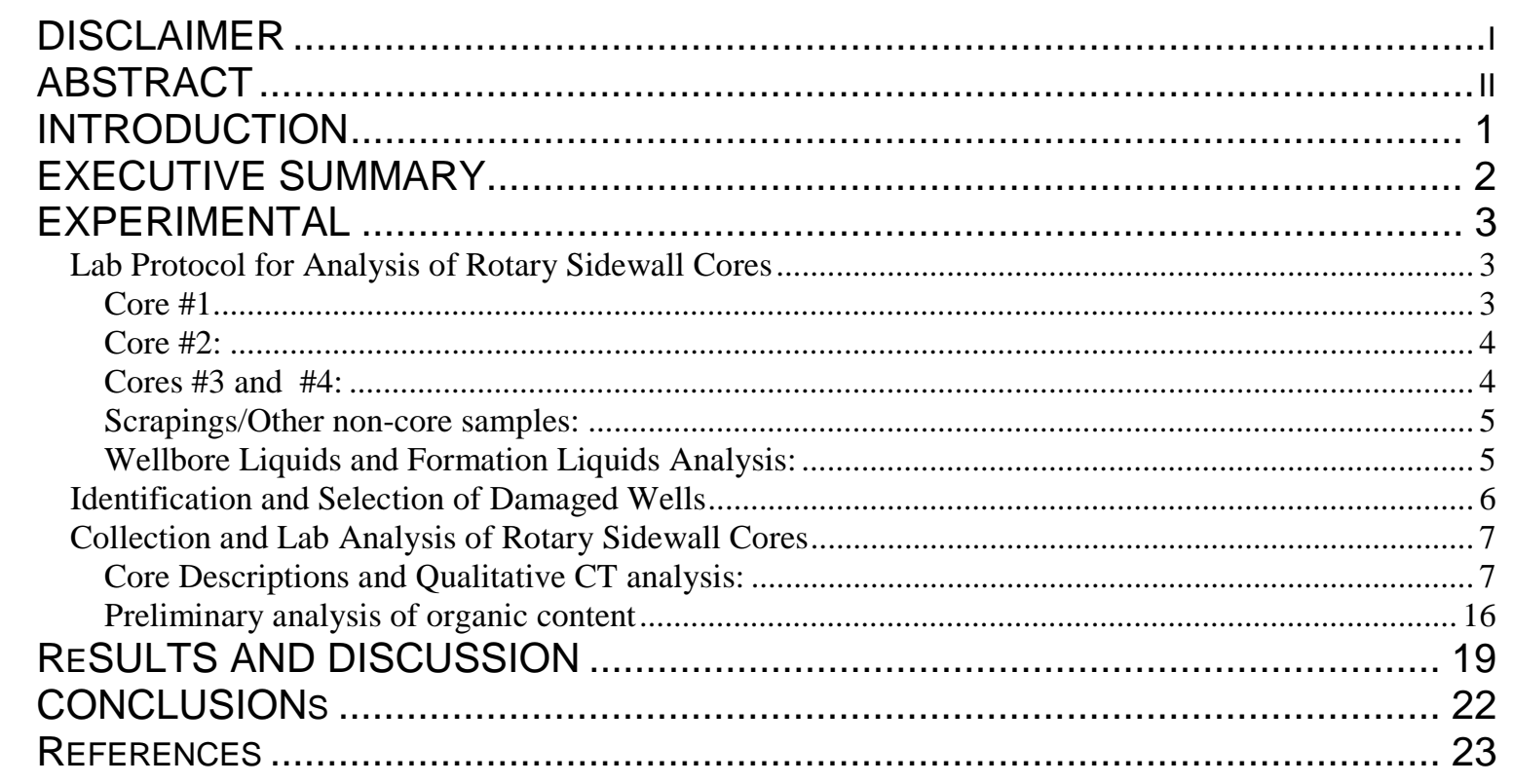




\section{INTRODUCTION}

The gas storage industry uses over 400 reservoirs and 17,000 wells to store and withdrawal gas. It is thus a significant contributor to gas supply in the United States. It is generally accepted that many gas storage wells show a loss of deliverability each year due to numerous damage mechanisms.

This problem has been studied previously (GRI/DOE studies by Mauer, Halliburton, and Schlumberger Holditch - Reservoir Technology Consulting Services). These studies estimated that up to one hundred million dollars are spent each year to recover or replace lost deliverability. The expenditures include both drilling new wells and stimulating/remediating existing wells. The American Gas Association estimates a deliverability loss of approximately 3.2 Bscf/D per year in the storage industry.

Thus, there is a great potential for restoring the capability of existing wells that are not being treated, for reducing the cost of deliverability enhancement by reducing the number of infill/replacement wells, for reducing remediation costs, and/or developing technology to mitigate or eliminate damage from occurring.

The GRI/DOE Halliburton study identified the primary mechanisms that may be responsible for loss of deliverability over time in gas storage wells. They defined testing procedures in storage wells and in the laboratory to identify potential damage mechanisms. The Halliburton study found eight major categories of potential damage mechanisms. The study discussed, in general, the possible reactions that need to occur to create the damage, but the study did not address the exact cause of damage or the most likely period of damage, i.e., during the injection or withdrawal cycle, how to prevent or mitigate the damage, and/or how to eliminate the damage from occurring in the future.

Thus, this contract serves to expand the effort Halliburton started and compliments the current GRI gas storage project. We expect to identify the exact damage mechanism and the optimal remedial, mitigative, and/or preventative measure both by laboratory testing and field application. The long-term effectiveness of the remediation treatment will be quantified based on damage mechanism and geochemical environment. A benefits study will extrapolate the results to the entire U.S. storage industry. The commercialization aspects of the diagnostic and remediation procedures will also be determined in the study. 


\section{EXECUTIVE SUMMARY}

The gas storage industry is a significant contributor to gas supply in the United States. The American Gas Association estimates that deliverability losses of approximately 3.2 Bscf/D per year occur in the storage industry due to numerous damage mechanisms. Previous studies estimate that up to one hundred million dollars are spent each year to recover or replace this lost deliverability. Thus, there is a great potential for restoring deliverability in existing wells, reducing deliverability enhancement costs and/or developing technology to mitigate or eliminate damage from occurring.

Prior studies have identified the primary mechanisms that may be responsible for deliverability loss in gas storage wells, and defined procedures to identify potential damage mechanisms. Although these studies discussed, in general, the possible reactions that need to occur to create the damage, they did not address the exact cause of the damage, determine when it occurs (injection or withdrawal) cycle, or determine how to prevent or mitigate the damage.

This research serves to expand prior efforts to identify the specific damage mechanism and the optimal remedial, mitigative, and/or preventative measure both by laboratory testing and field application.

There are four primary goals of contract DE-FG26-99FT40703:

1) Better understand how and why a specific iron-related inorganic precipitant, siderite, occurs at the reservoir/wellbore interface in gas storage wells.

2) Test potential prevention and remediation strategies related to these two damage mechanisms in the laboratory.

3) Demonstrate in the field, cost-effective prevention and remediation strategies that laboratory testing deems viable.

4) Investigate new technology for the gas storage industry that provides operators with a cost effective method to reduce non-darcy turbulent flow effects on flow rate.

We will demonstrate the diagnostic technique for determining the damage mechanism and evaluate remedial techniques in the laboratory as well as in actual gas storage reservoirs. We will accomplish this by performing extensive lab analyses of rotary sidewall cores, testing potential remediation strategies in the lab, and demonstrating the applicability of the remediation treatments in the field. Achieving the above goals will enable the underground gas storage industry to more cost-effectively mitigate declining deliverability in their storage fields. Work completed to date includes the following:

1) Solicited potential participants from the gas storage industry.

2) Selected participant experiencing damage from inorganic precipitates.

3) Developed laboratory testing procedures.

4) Collected and analyzed cores from two National Fuel Gas wells in the Summit Field.

5) Investigated methods to remove damage identified in cores.

6) Identified three wells with same damage mechanism (inorganic precipitates).

7) Designed a field plan for damage removal in the three candidate wells.

8) Identified potential method to prevent damage from reoccurring after well stimulation.

9) Continued investigating methods to reduce non-darcy turbulent effects 


\section{EXPERIMENTAL}

\section{Lab Protocol for Analysis of Rotary Sidewall Cores}

The protocol for lab analyses of rotary sidewall cores was finalized by Dr. Phil Halleck. Dr. Halleck is a Professor of Petroleum and Natural Gas Engineering at Penn State. He directed the laboratory investigations of the cores. The protocol, as well as the rationale for the various procedures is outlined below.

The sidewall coring program requires four sidewall cores from each well, plus samples of formation rock in its original condition. The objectives of the proposed testing performed on each core are summarized below, as well as the procedure employed to perform the stated testing

\section{Core \#1}

Objective - Damage Characterization

Slab the core lengthwise with a diamond saw, and perform the following analyses on the first half of core \#1:

- Solvent Extract

- Gas Chromatograph Mass Spectrometer (GCMS) analysis on organics from this half to determine compounds present

Prepare thin section

Perform Scanning Electron Microscopy/Energy Dispersive X-Ray Analysis (SEM/EDAX) to map texture and identify inorganic scale elements

Examine with petrographic microscope for mineralogy and texture

These tests are designed to identify the presence of various mineral scales and organic compounds in the pore structure and on the surface of the core. Solvent extraction using appropriate solvents in Soxlet apparati will dissolve any organic material and condense it into a separate container for analysis. The amount of organic material extracted from a given volume of rock allows determination of how much pore space was occupied by the organic material. The GCMS, or gas chromatograph mass spectrometer, is used to separate the various components of the resulting mixture and determine their molecular weights and thus their composition. These data are useful in determining the source of the material as native organic liquids, compressor oil, production chemical, or reaction products of one of these with other chemical agents. If necessary, carbon isotope analysis is available to assist in determining the age of the organics.

The thin section will be used primarily for SEM (scanning electron microscope) and EDX (energy dispersive X-ray) analysis. These will provide a microscopic view of the pore structure of the rock as well as maps of the distribution of the specific elements composing any inorganic precipitates. The result is determination of the distribution of scale minerals in the pore structure, which will assist in determining the scale's affect on permeability. These data will be supplemented with bulk analysis of cation and anion composition as described below. Thin sections will also be used for standard petrographic examination of the rock's texture, mineralogy and pore structure.

Data from the sidewall core will be compared with a rock sample in its original condition. This is necessary both to evaluate the geochemical environment and to quantify how much of each mineral has been deposited by storage and production operations and how much may have been originally present. 
Perform the following on the second half of core \#1:

Perform gas permeability measurement on the half core

Slice second half crosswise in $1 / 4$-in increments

Retest permeability after taking each slice

Solvent extract each 1/4-inch increment

Perform X-Ray Diffraction (XRD) analysis on each increment

Perform Inductively Coupled Plasma (ICP) and ion chromatographic analyses on each increment

Perform Total Organic Carbon (TOC) measurement on liquids from each increment

These tests are designed to further identify the nature of any inorganic and organic materials on and in the formation rock, and to provide a course map of the severity of potential plugging. The gas permeability tests give the average permeability of the core as each slice of material is removed. The change in permeability after taking each slice allows determination of the permeability of the slice, thus obtaining a coarse map of permeability as a function of distance from the sand face. Analyzing each slice separately for the presence of organic and inorganic plugging materials allows the amounts of these compounds to be mapped as a function of distance from the sand face. XRD, or X-ray diffraction analysis, is used to identify the presence of specific minerals present in the rock. These are identified by their crystal structures as revealed by their diffraction patterns. Interpretation is assisted by knowledge of the cations and anions present. These data come from the EDX measurements described above and from ICP (Inductively Coupled Plasma) spectrophotometer analysis of cations. This test is performed by dissolving the mineral phases in appropriate acids to form a solution. The solution is ionized in a plasma and the light emissions analyzed to determine the amounts of specific cations present. Ion chromatography is used to separate and quantify anions such as CO3-2, HCO3-, and SO4-2. TOC (or total organic carbon) measurements on each slice will determine how much organic material is present, again, as a function of distance from the sand face.

\section{Core \#2:}

Objective - Relation of permeability damage to observed plugging mechanisms.

Perform gas permeability on entire core in both directions

Solvent extract entire core

Retest permeability

\section{Cores \#3 and \#4:}

Objective - Evaluation of remediation techniques.

Perform gas perm on entire core in both directions

Treat core with selected remedial method

Acidization

Miscible solvent

Heat/Pressure

Mechanical removal of the sandface

Re-measure gas permeability

Several cycles of treatment may be possible 
If appropriate, evaluate post-treatment sample as for core \#1

These tests are designed to determine the effectiveness of treatments that might be applied in the field. A special vessel will be fabricated to apply these treatments in a manner consistent with the downhole environment. Acids or miscible solvents will be injected into the sandface of the core. The core itself will be backed by additional formation rock so that spent acids and solvents are pushed through the core and into the backing rock. The spent treatment fluids will be recovered back though the test core to simulate actual down-hole processes. After completion of each treatment, gas permeability will be remeasured to determine the effects of the treatment. Due account will be taken of relative permeability effects.

\section{Scrapings/Other non-core samples:}

Objective: Evaluate lower-cost testing alternatives.

Obtain samples from perforations and/or wellbore wall
Extract hydrocarbons
Perform GCMS to determine hydrocarbons present
Perform XRD on inorganic material
Perform cation/anion analysis on same material

These tests are designed to evaluate the effectiveness of lower-cost testing alternatives. The sidewall cores required for the above tests are quite expensive and simpler, more cost effective methods of determining the damage mechanisms are required. The intent of these tests is to evaluate whether cheaper, but less well-defined samples can be used to obtain the same information. The tests described have the same purpose as those run on sidewall core, except that permeability itself is not measured and distribution of damage away from the sand face is not obtained. The results of these tests will be compared with those from the sidewall cores.

\section{Wellbore Liquids and Formation Liquids Analysis:}

Objective: Supplement mineralogical/chemical data obtained from formation mineralogy and pore fluid analyses

Perform ICP and ion chromatographic analyses on well water Obtain total ion content and $\mathrm{Ph}$ to define environment

The intent of these tests is to supplement the mineralogical and chemical data obtained from formation mineralogy and pore fluid analyses. The combined data, plus historical records of production chemicals and previous remediation treatments used, form the basis for characterizing the geochemical environment. These data are used to establish the precipitation reactions and phase behavior involved in depositing the observed scale. The intent is to go beyond remediation to develop operating procedures that prevent reoccurrence of permeability damage.

Dr. Halleck coordinated the design, construction, and calibration of the equipment required for the above testing. In addition, test runs were made on non-study cores to iron out operational, procedural, and/or technical problems prior to testing the study cores. 


\section{Identification and Selection of Damaged Wells}

Multi-rate pressure transient test analyses constituted the primary tool for identification and quantification of the type and amount of damage level in candidate wells. National Fuel Gas selected 9 wells to run multi-rate pressure transient tests in, based on their assessment of how the current deliverability potential compared with the original deliverability potential measured when the well was first drilled. These tests were performed in March of 2002. A summary of the results of these tests is shown in Table 1 below.

Table 1: Summary of Pressure Transient Test Analysis Results

\begin{tabular}{|c|r|r|c|c|c|r|r|r|r|r|}
\cline { 2 - 11 } \multicolumn{1}{c|}{} & \multicolumn{4}{c|}{ Input Values } & \multicolumn{1}{c|}{ Output Values } \\
\hline Well & $\mathrm{h}_{\text {net }}$ & \multicolumn{1}{c|}{ phi } & $\mathrm{S}_{\mathrm{w}}$ & $\mathrm{r}_{\mathrm{w}}$ & \multicolumn{1}{c|}{$\mathrm{SG}$} & $\mathrm{AOF}$ & $\mathrm{K}$ BH & \multicolumn{1}{c|}{$\mathrm{Kh}$} & \multicolumn{1}{c|}{$\mathrm{S}_{\mathrm{m}}$} & $\mathrm{D}$ \\
\hline Summit 1515 & 1.5 & $14.0 \%$ & $20.0 \%$ & 0.255 & 0.58 & 1,265 & 1,575 & 1050 & 42.6 & 0.0335 \\
\hline Summit 1524 & 3.0 & $14.0 \%$ & $20.0 \%$ & 0.255 & 0.58 & 785 & 966 & 322 & 69 & 0.0097 \\
\hline Summit 1527 & 13.0 & $14.0 \%$ & $20.0 \%$ & 0.255 & 0.58 & 10,425 & 2,418 & 186 & $\mathrm{~N} / \mathrm{A}$ & $\mathrm{N} / \mathrm{A}$ \\
\hline Summit 1551 & 5.0 & $14.0 \%$ & $20.0 \%$ & 0.255 & 0.58 & 20,442 & 5,085 & 1017 & $\mathrm{~N} / \mathrm{A}$ & $\mathrm{N} / \mathrm{A}$ \\
\hline Summit 1554 & 6.0 & $14.0 \%$ & $20.0 \%$ & 0.255 & 0.58 & 4,757 & 1,800 & 300 & 2.5 & 0.0038 \\
\hline Summit 1565 & 2.0 & $14.0 \%$ & $20.0 \%$ & 0.255 & 0.58 & 7,992 & 1,632 & 816 & $\mathrm{~N} / \mathrm{A}$ & $\mathrm{N} / \mathrm{A}$ \\
\hline Summit 1574 & 4.0 & $14.0 \%$ & $20.0 \%$ & 0.255 & 0.58 & 509 & 1,240 & 310 & $\mathrm{~N} / \mathrm{A}$ & $\mathrm{N} / \mathrm{A}$ \\
\hline Summit 1585 & 2.0 & $14.0 \%$ & $20.0 \%$ & 0.255 & 0.58 & 6,252 & 885 & 442.5 & -1.6 & 0.0009 \\
\hline Summit 1589 & 3.0 & $14.0 \%$ & $20.0 \%$ & 0.255 & 0.58 & 4,343 & 2,295 & 765 & 10.8 & 0.0051 \\
\hline
\end{tabular}

Based on this testing and other data, Summit Wells 1527, 1515, 1524, and 1589 were identified as stimulation candidates. Summit 1515 was subsequently replaced with Summit 1522 due to operational issues. Although no pressure transient test was run in Summit 1522, NFG selected this well as an alternate, based on evidence they had that deliverability deterioration had occurred.

Summit Well 1527 was drilled in 1956, completed in the Oriskany formation as an open hole well, and converted to storage in 1960. The well has 7" production casing set at 2277 feet and was originally drilled to a TD of 2285 feet. In 1992, a hydroblast treatment was performed. In August of 1999, a second hydroblast treatment was attempted in the well after testing indicated a mechanical skin factor of 26 . Attempts to pump fluids into the reservoir failed, due to excessive injection pressures. However, acid was spotted across the reservoir. Post-treatment testing indicated that the mechanical skin was reduced to about 8 . NFG subsequently decided to deepen Summit Well 1527, and in August of 2000, the well was deepened to a TD of 2310 feet. During this workover, sidewall cores were recovered from both the old portion of the hole and the new portion of the hole, allowing a comparison of virgin formation with formation that had been used for 40 years.

Summit Well 1522 was drilled in 1956, completed in the Oriskany formation as an open hole well, has 7" production casing and was drilled to a TD of 2390 feet.

Summit Well 1524 was drilled in 1956, completed in the Oriskany formation as an open hole well, has 7" production casing set at 2372 feet and was drilled to a TD of 2389 feet.

Summit Well 1589 was drilled in 1955, completed in the Oriskany formation as an open hole well, has 7" production casing set at 2120 feet and was drilled to a TD of 2338 feet. 


\section{Collection and Lab Analysis of Rotary Sidewall Cores}

Plans were made to recover sidewall cores from Summit Well 1527 and Summit Well 1524. The sidewall cores from Summit Well 1527 were collected during deepening operations in August 2000. The sidewall cores from Summit Well 1524 have not been recovered to date. It is anticipated that they will be recovered in 2002 . The following discussion relates to analysis of sidewall cores from Summit Well 1527 only.

Penn State has received eight sidewall core samples taken from the National Fuel Gas Summit Field well 1527. The cores were photographed and, where possible, scanned by X-ray computed tomography (CT).

There are clear distinctions between the cores taken from the old and new sections of the well. The former are gray in color as opposed to the light tan coloration in cores from the new section. Most of the cores from the older, upper section show evidence of previous acid treatments as open fractures where carbonate material has apparently been dissolved away. These features are not present in cores from the newer section. On the other hand, X-ray CT shows higher concentrations of a high-density material in the cores from the newer section. This high-density material may be the carbonate material (calcite or siderite) that was dissolved from the upper section.

Three of the cores, two from the new section and one from the older section were damaged or crushed to the point that no permeability measurements will be possible. In addition, all but one of the cores from the upper section contain large open fractures or vugs, apparently from acidization. This leaves only two cores for which permeability measurements will be possible.

Two of the broken samples, one each from the new and old sections of the well, have been subjected to pyrolysis, analyzing the evolved vapors using a gas chromatograph, mass spectrometer. These analyses reveal very low levels of organic material, dominantly paraffinic compounds, although others are also present. Elemental sulfur is also present in the core from the new section, confirming previous observations. Pyrolysis of material previously extracted using methylene chloride shows that the solvent extraction process alone should be capable of removing the organics in future tests.

The amounts of organic material and their nature suggest that these are not the causal mechanism of permeability reduction. We are proceeding with analysis of inorganic material using X-ray diffraction and scanning electron microscopy with $\mathrm{x}$-ray fluorescence analysis.

Core Descriptions and Qualitative CT analysis:

Each of the cores was photographed and scanned in three dimensions using X-ray CT analysis. The results are summarized below. The positions of the cores are marked on the accompanying well log (Fig. 1). 


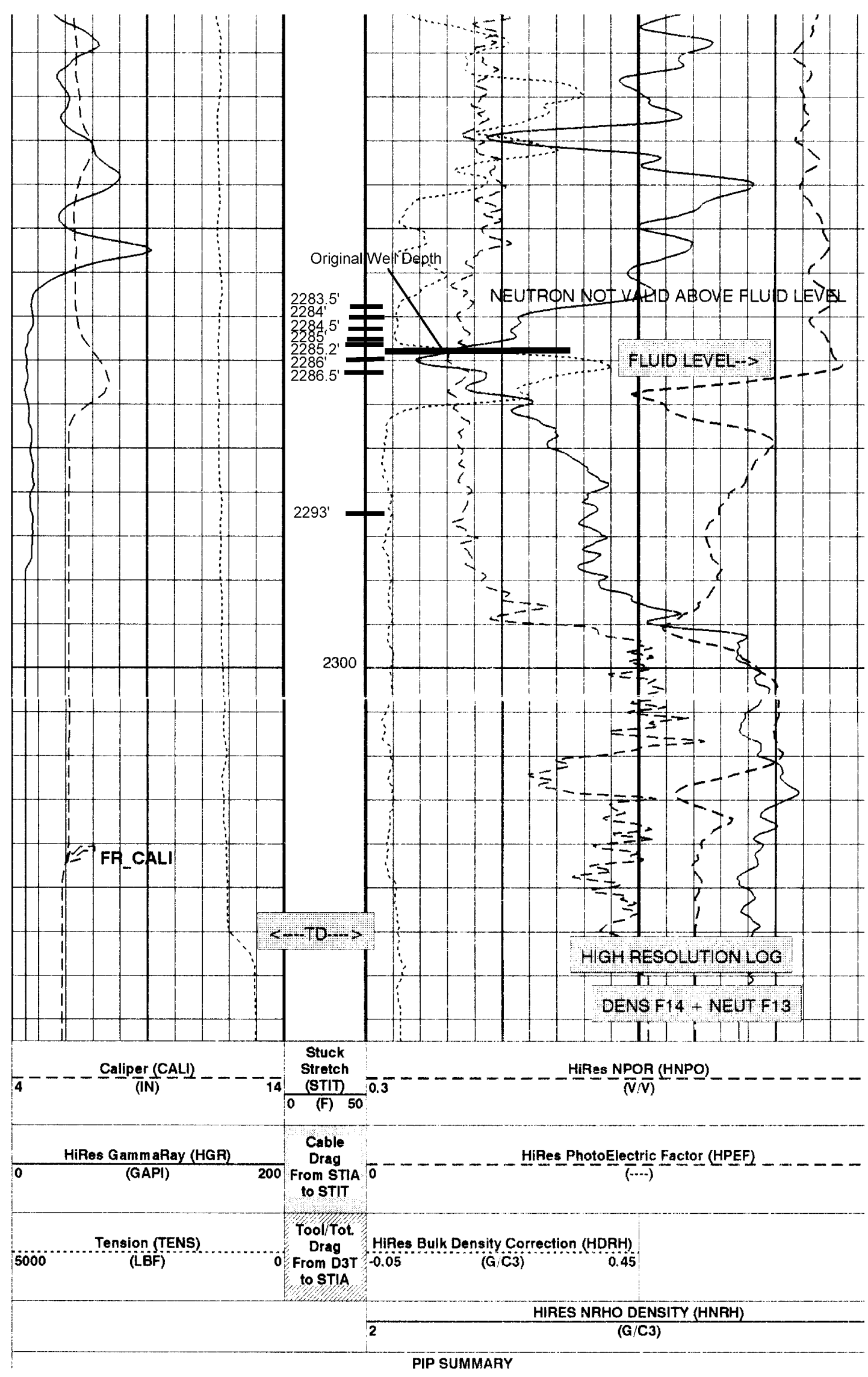

Figure 1: Summit Well 1527 Log Showing Sidewall Core Locations 
Core \#1 (Fig. 2) was taken at a depth of 2283.5 feet The core is a sandstone, dark gray in color, $23.3 \mathrm{~mm}$ in diameter and $42 \mathrm{~mm}$ long. One end is terminated by a smooth curved surface indicating the sand face of the well. The other end is a broken surface where the core was broken off. Large vugs are present with apparent remnants of calcite fracture filling. Previous acid treatments have apparently dissolved most of the calcite, leaving open spaces.

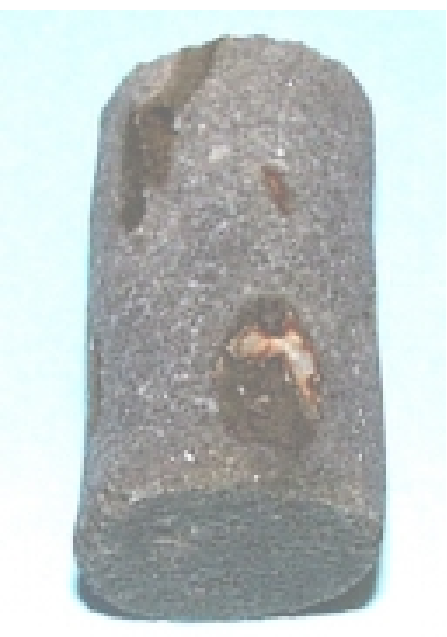

Figure 2: Photograph of Core \#1

The X-ray ct images of Core \#1 (Fig. 3) are at 2-mm spacing along the core, starting at the well's sand face from left to right. Red indicates high density or atomic number while blue/black represents low density or voids. There is a concentration of high-density material in the first $1.4 \mathrm{~mm}$ of rock. An empty fracture is clearly visible starting with the seventh image.

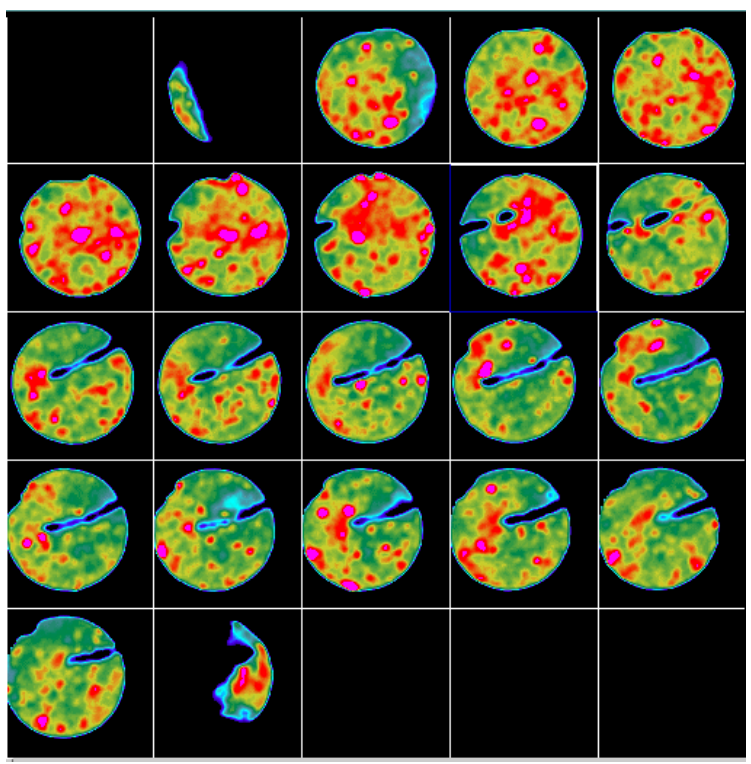

Figure 3: X-Ray CT Images of Core \#1 
Core \#2 (Fig. 4) was taken at a depth of 2284 feet The core is a sandstone, dark gray in color, $23.3 \mathrm{~mm}$ in diameter and $37 \mathrm{~mm}$ long. One end is terminated by a smooth curved surface indicating the sand face of the well. The other end is a broken surface where the core was broken off. The core appears uniform with no visible vugs or fractures.

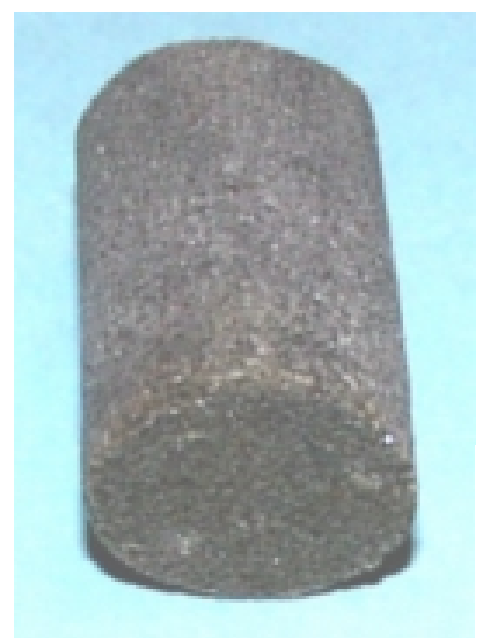

Figure 4: Photograph of Core \#2

The X-ray ct images of Core \#2 (Fig. 5) are at 2-mm spacing along the core, starting at the well's sand face from left to right. The few red spots indicate high density or atomic number while blue/black represents low density or voids. The rock appears uniform with no evidence of fractures or dissolution features. Overall density appears lower than the core at 2283.5 feet.

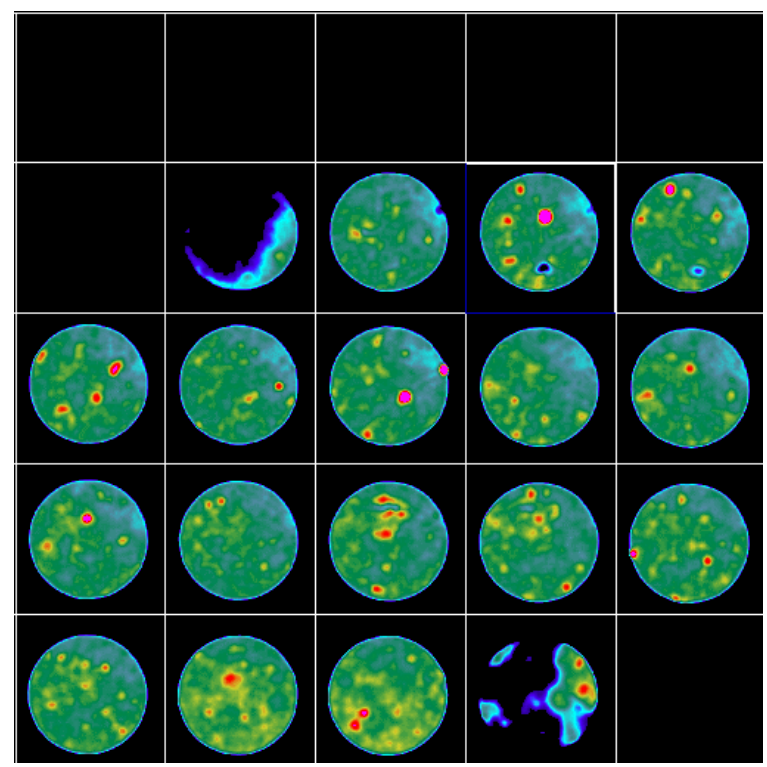

Figure 5: X-Ray CT Images of Core \#2 
Core \#3 (Fig. 6) was taken at a depth 2284.5 feet. The core is a sandstone, dark gray to brown in color, $23.4 \mathrm{~mm}$ in diameter and $38 \mathrm{~mm}$ long. One end is terminated by a smooth curved surface indicating the sand face of the well. The other end is a broken surface where the core was broken off. A major dissolution feature is present on the side of the core along its entire length.

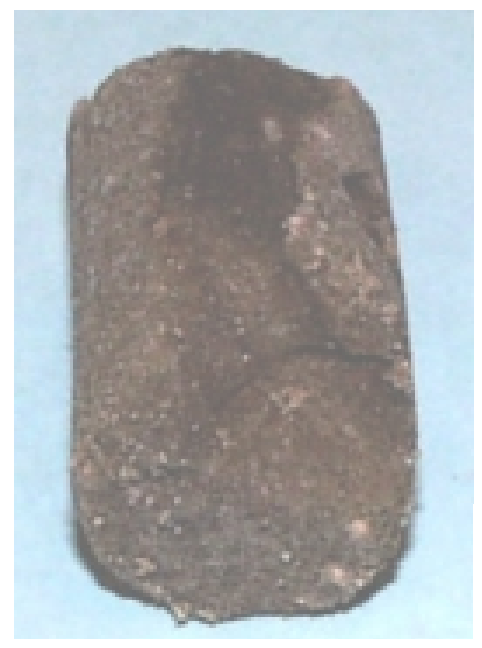

Figure 6:Photograph of Core \#3

The X-ray ct images of Core \#3 (Fig. 7) are at 2-mm spacing along the core, starting at the well's sand face from left to right. Red areas present in the first 12 slices indicate high density or atomic number while blue/black represents low density or voids. The red areas decrease in portion of the core furthest from the sand face. In addition to the dissolved volume visible in the photo, the scans reveal a second internal void of the same magnitude.

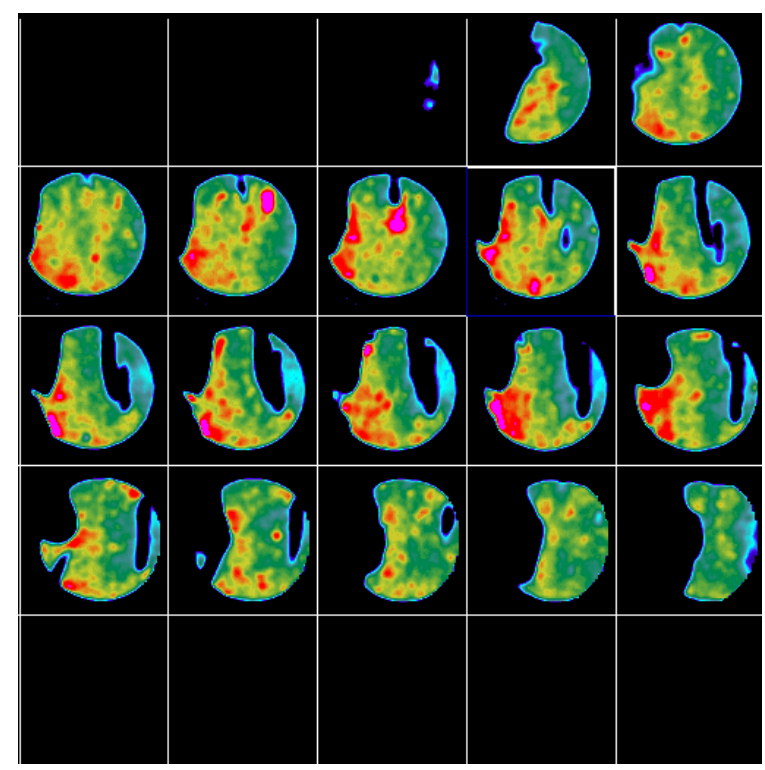

Figure 7: X-Ray CT Images of Core \#3 
Core \#4 (Fig. 8) was taken at a d Depth 2285 feet. The core is a sandstone, dark gray in color, $23.5 \mathrm{~mm}$ in diameter and $41 \mathrm{~mm}$ long. One end is terminated by a smooth curved surface indicating the sand face of the well. The other end is a broken surface where the core was broken off.

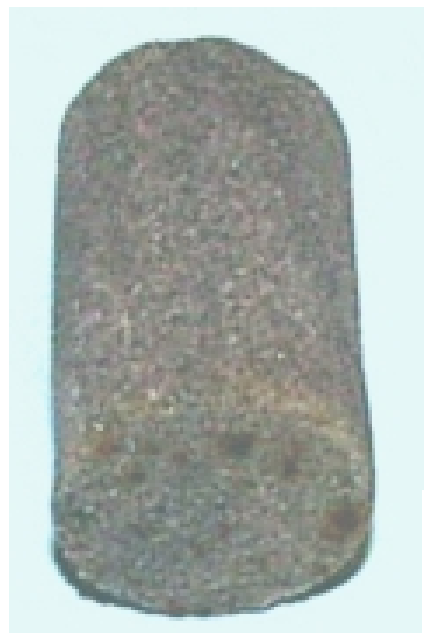

Figure 8: Photograph of Core \#4

The X-ray CT images (Fig. 9) of Core \#4, again at 2-mm spacing along the core, reveal a hidden empty fracture in the interior starting about $8 \mathrm{~mm}$ into the core. A high-density (red) feature in the forth and fifth images correspond with the plane of the fracture in subsequent images and may represent the material that was dissolved. In general there is less of the high-density material present in this core. It closely resembles core \#2 except for the fracture.

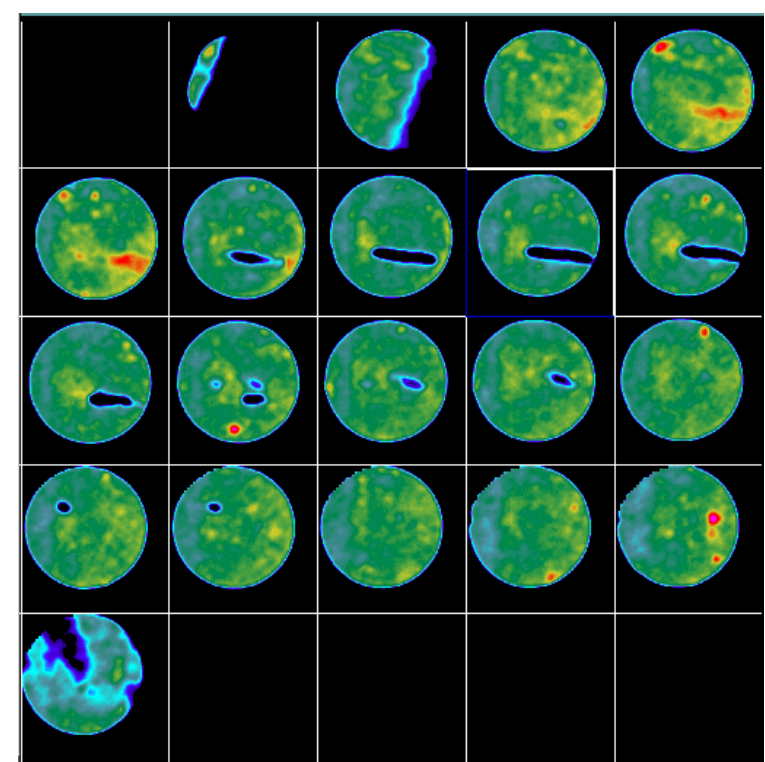

Figure 9: X-Ray CT Images of Core \#4 
Core \#5 was taken at a depth 2285.2 feet. The core is a sandstone, dark gray in color, $23.5 \mathrm{~mm}$ in diameter and $\sim 22 \mathrm{~mm}$ long. One end is terminated by a smooth curved surface indicating the sand face of the well. The core is fractured and the fracture surfaces do not match. An additional piece is missing from the sand face. The material appears homogenous. No X-ray CT scans were taken

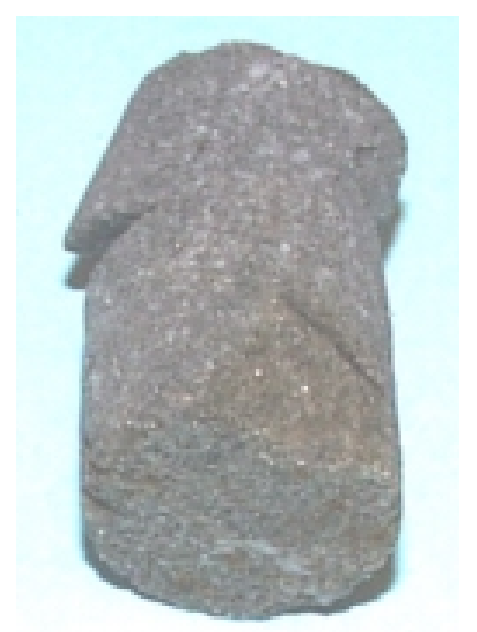

Figure 10: Photograph of Core \#5

Core \#6 (Fig. 11) was taken at a depth 2285.2 feet. The core is a sandstone, tan color, $22.5 \mathrm{~mm}$ in diameter and $23.5 \mathrm{~mm}$ long. Both ends are fracture surfaces and there is an additional axial fracture at one end. This is apparently the first sidewall core from the newly drilled section of the well and there is a distinct difference in color.

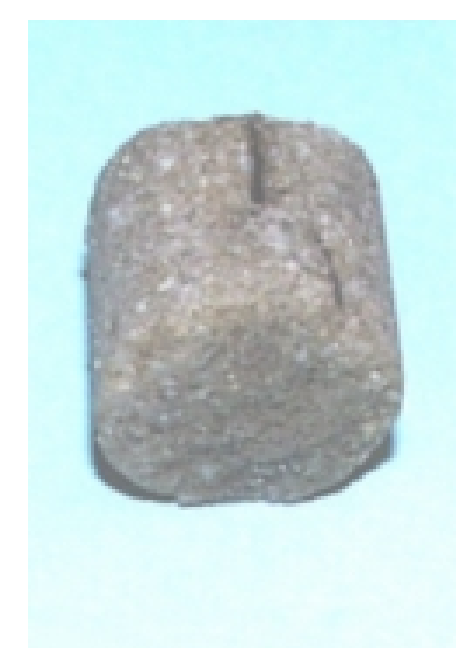

Figure 11: Photograph of Core \#6 
The X-ray CT images (Fig. 12) of Core \#6 are at 2-mm spacing along the core, starting at the well's sand face from left to right There is significantly more high-density (red) material present than in many of the shallower cores. The fracture is clearly visible in the fourth through seventh images.

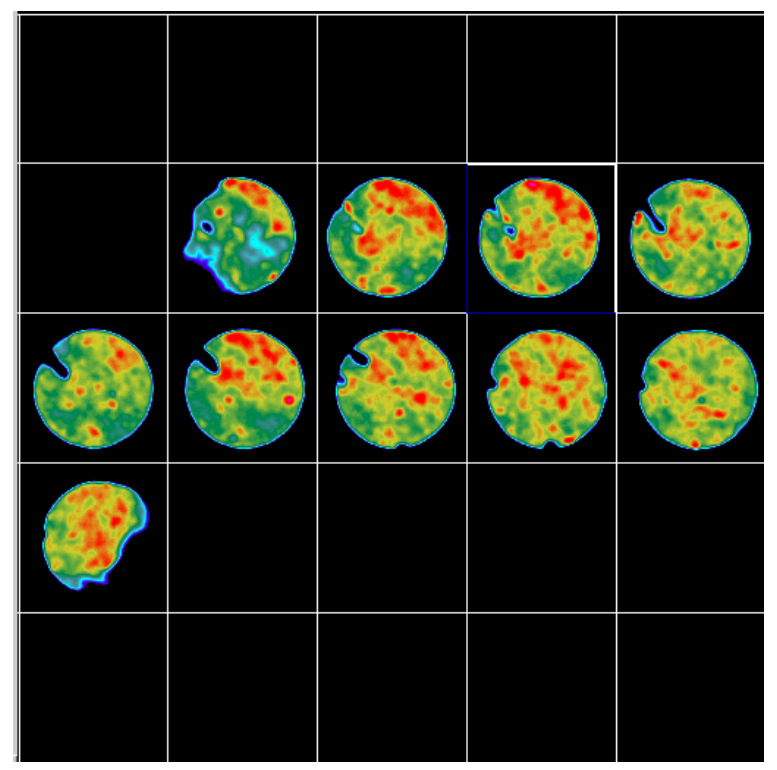

Figure 12: X-Ray CT Images of Core \#6

Core \#7 (Fig. 13) was taken at a depth 2286.5 feet. The core is a sandstone, tan color. The core is largely fragmented with only one small piece of full diameter. No X-ray CT images were taken.

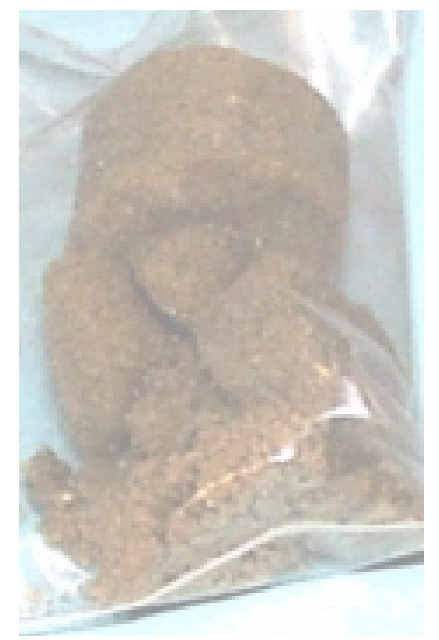

Figure 13: Photograph of Core \#7 
Core \#8 (Fig. 14) was taken at a depth of 2293 feet. The core is a sandstone, tan in color, $23.3 \mathrm{~mm}$ in diameter and $41 \mathrm{~mm}$ long. One end is terminated by a smooth curved surface indicating the sand face of the well. The other end is a broken surface where the core was broken off. The sample appears uniform, although mineralized veins are evident on one side.

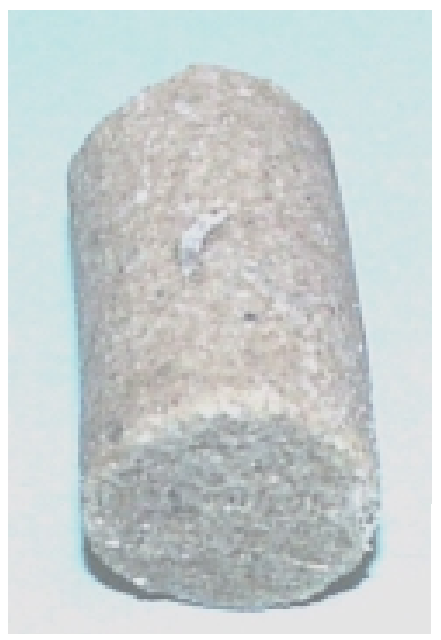

Figure 14: Photograph of Core \#8

The X-ray ct images are $2 \mathrm{~mm}$ thick starting at the well's sand face from left to right. There is significantly more high-density (red) material present than in many of the shallower cores. There is no evidence of fractures or dissolution features.

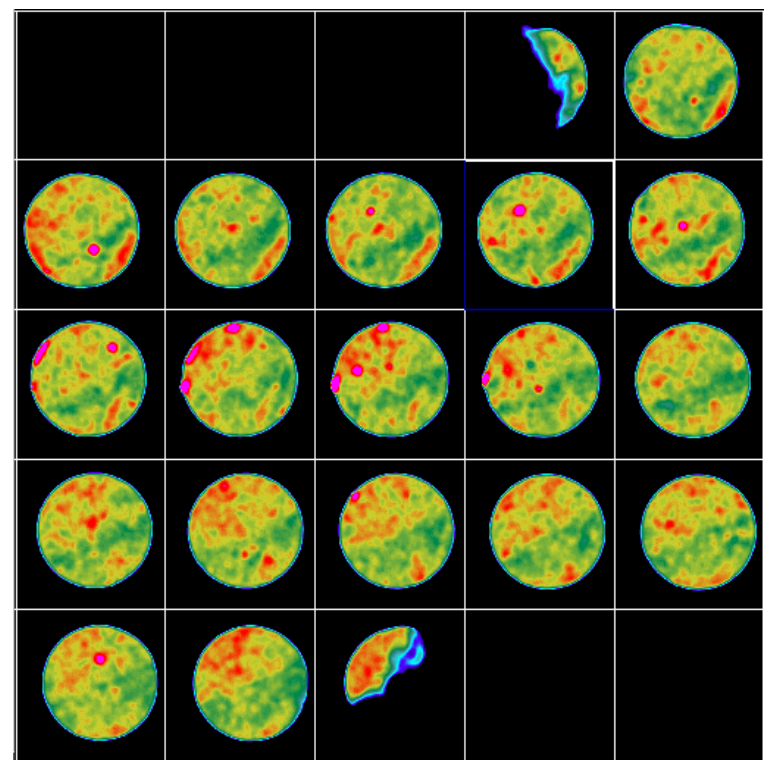

Figure 15: X-Ray CT Images of Core \#8 


\section{Preliminary analysis of organic content}

The extractable organic matter in cores 2285.2' and 2286.5' were analyzed employing two methods: (i) pyrolysis-gas chromatography/mass spectrometry (py-GC/MS) and (ii) extraction with organic solvent. Both methods yielded a paucity of compounds comprised primarily of relatively heavy aliphatic hydrocarbons.

For analysis by Py-GC/MS, approximately $50 \mathrm{mg}$ of sample was loaded into a quartz pyrolysis boat then inserted into a Chemical Data Systems Pyroprobe 1000. The probe was then inserted directly in to the injection port (maintained at $280^{\circ} \mathrm{C}$ ) of a Hewlett Packard 5890 gas chromatograph.

Once in the injection port, the pyroprobe was ramped to a temperature of $610^{\circ} \mathrm{C}$ at $5^{\circ} \mathrm{C} / \mathrm{ms}$. Volatile and cleaved organic compounds are swept into the gas chromatograph for separation and identification by the HP 5971 mass spectrometric detector (Fig. 16). Pyrolyzate abundances for both samples showed remarkably low total organic carbon content $(\sim 0.5-.05 \%)$. The major compounds observed were long chain alkanes ranging in carbon number from $\mathrm{C} 20$ to $\mathrm{C} 45$ with the bulk of the pyrolyzate represented by an unresolved complex mixture (UCM) also representative of aliphatic hydrocarbons. A less abundant suite of chlorinated alkanes was observed for both samples.

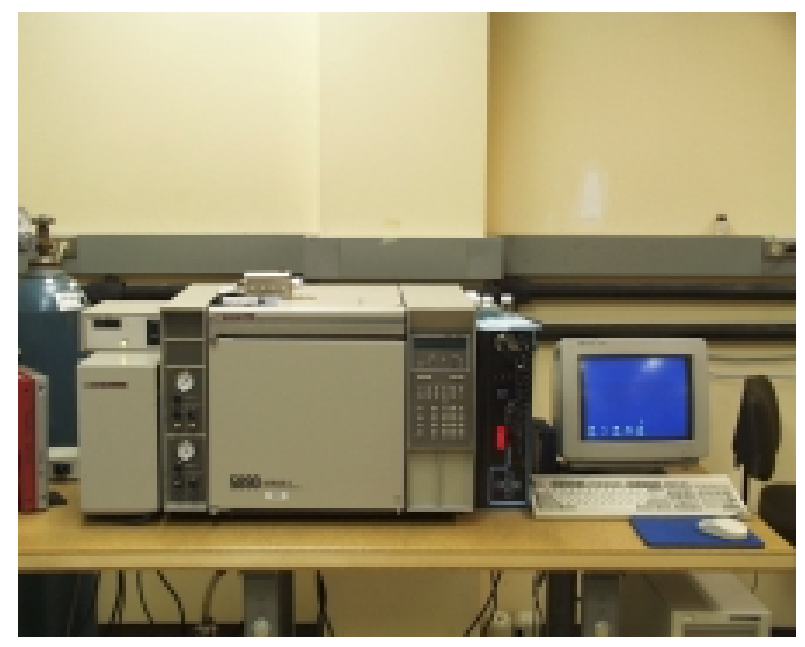

Figure 16: HP 5971 Mass Spectrometric Detector

Additional samples from each of the cores were Soxhlet extracted with methylene chloride for 48 hours to isolate volatile organic compounds. Extraction yields were $0.18 \%$ and $0.10 \%$ by weight for the upper and lower cores respectively.

The extracts were then further processed by passing samples through an aluminum oxide column to isolate GC-amenable compounds. Yields of this process as a fraction of total sample extracted $(26.141 \mathrm{~g}$ and $25.231 \mathrm{~g})$ were $0.05 \%$ and $0.04 \%$ for the upper and lower cores, respectively. The sample extracts were then subjected to analysis by GC/MS for separation and compound identification. The instrument used was a Shimadzu QP5000 (Fig. 17). 


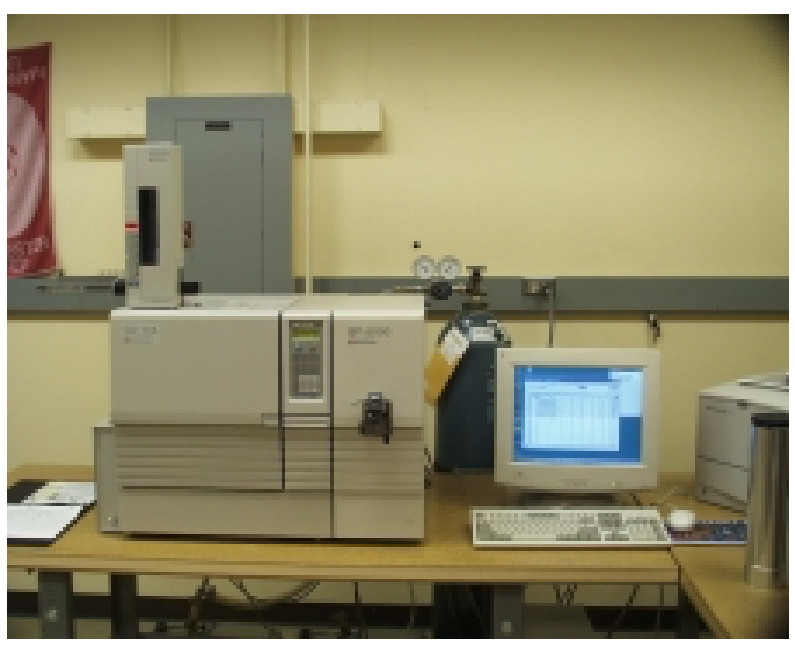

Figure 17: Shimadzu QP5000

The resulting chromatogram from upper core is shown below (Fig 18), and indicates a homologous series of straight chain alkanes ranging between 20 and 45 carbons comparable to the results of py-GC/MS analyses. Again, the majority of compounds elute as an UCM comprised of aliphatic hydrocarbons. A notable difference was the presence of orthorhombic sulfur (S8) in the extract of the upper core sample.

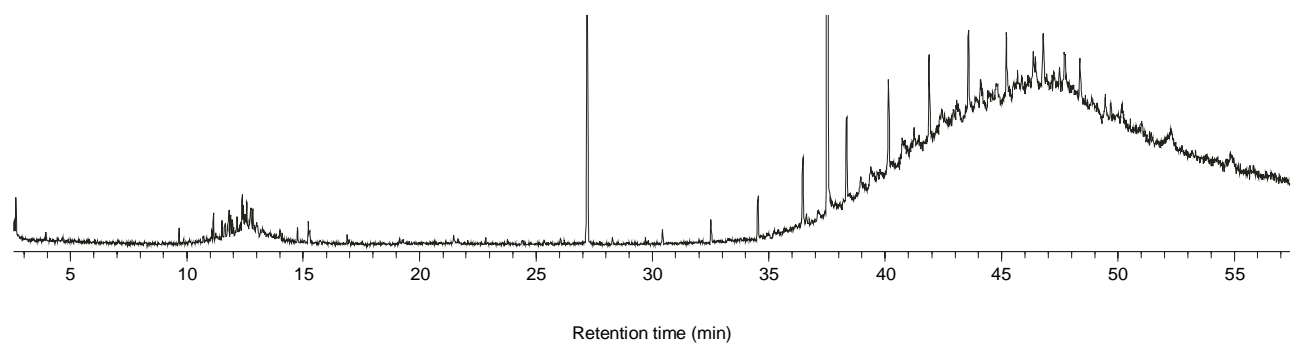

Figure 18: GC/MS trace for Summit well 1527, core 2285.2'

Both samples were also subjected to analysis utilizing a simulated distillation column and high temperature GC, which allows for observation of relatively 'heavier' hydrocarbons. Chromatograms showed an extended homologous series of straight chain alkanes ranging between $\mathrm{C} 20$ and $\mathrm{C} 60$ with evidence of an asphaltene-like component eluting at relatively high temperature $\left(450^{\circ} \mathrm{C}\right)$.

The solid residue following extraction with methylene chloride was analyzed py-GC/MS. No compounds were observed which means that solvent extraction was sufficient to the removal of organic material.

Failing to find organic plugging agents, we plan to proceed with cation/anion analyses of the samples, comparing the fresh cores with the older damaged ones. Earlier studies indicate the presence of siderite (FeCO3), and we will be looking specifically for the presence of this and other related chemical in both samples. We will also expect to use X-ray diffraction to identify specific mineral phases. 
The core samples delivered to NFG were all from the new portion of the wellbore. Stressed (to $800 \mathrm{psi}$ ) porosities in these samples range from 10-16\% and the Klinkenberg permeabilities range from 300-1000 md over the interval 2285.5 - 2297'. Details of these analyses are included in Appendix 1 of this report. 


\section{RESULTS AND DISCUSSION}

\section{Selection of Geochemical Environment for Study}

Several of the subtasks associated with Task \#1 (Table 2) in our proposal have been completed. Data and reports from several previous GRI, DOE, FETC, and other industry studies have been reviewed where pertinent ${ }^{1-4}$. Specifically, GRI/DOE studies by Mauer, Halliburton, and other authors related to damage mechanism identification protocol, identification and estimation of damage levels in storage wells, frequency and success of remediation treatments used in the storage industry and novel stimulation techniques have been reviewed.

\section{TABLE 2: SUMMARY OF TASKS AND SUBTASKS}

\begin{tabular}{|c|c|}
\hline Task & Task Description \\
\hline 1 & $\begin{array}{c}\text { Select and characterize a study set of damage mechanisms in the natural } \\
\text { gas storage geologic/geochemical environment. }\end{array}$ \\
\hline 2 & $\begin{array}{c}\text { Develop conceptual strategies to mitigate or eliminate the selected } \\
\text { damage mechanisms. }\end{array}$ \\
\hline 3 & $\begin{array}{c}\text { Design and perform laboratory scale studies to evaluate conceptual } \\
\text { strategies with selection and refining of promising strategies. }\end{array}$ \\
\hline 4 & Budget Period I Report \\
\hline
\end{tabular}

In addition, we have selected the geochemical/geological environment to study, represented by NFG's Wells 1527, 1522, 1524, and 1589 in the Summit Field, located near Erie, PA. These wells are completed in the Oriskany sand, and some were part of a previous Halliburton damage mechanism study, and have been subject to testing and sampling over the last several years.

Historical and operational data related to NFG's Summit 1527 study well has been collected and reviewed. This information includes past pressure transient testing results, backpressure testing results, results of analyses of wellbore fluids and pipeline solids, past stimulation information, and information included in the Halliburton report.

Multi-rate pressure transient test analyses were performed in 9 wells suspected of having damage based on a comparison of current deliverability potential and the original deliverability potential. Results of these tests were previously presented (Table 1).

\section{Charactrization of Geochemical Environment}

Rotary sidewall cores from Summit Well 1527 were collected in October 2000, and analyzed. Based on the results of this testing, it appears that most of the damage occurs close to the wellbore, fractures are present in the reservoir, there is very little damage due to organic plugging materials, and the organic compounds that are present are mainly aliphatic hydrocarbons, long chain alkanes, and a very small amount of chlorinated alkanes.

A comparison of the cores from the old section of the wellbore with those from the newly drilled section of the wellbore suggests that prior stimulations were reasonably effective at removing iron-related damage. Nonetheless, some mechanical damage remains, and it appears to be iron-related damage. The color of the entire core differs, depending on whether it is from virgin formation or previously exposed formation. This may suggest 
that some damage occurs deeper in the formation. Notwithstanding this observation, the majority of the visible damage may occur within a few millimeters of the wellbore.

Based on testing conducted to date, we can state with some certainty the following facts:

1. The elements observed in the scale are and have been iron, calcium, magnesium, sodium, chlorine, sulfur, and oxygen (the presence of carbonate is chemically uncertain).

2. The wells have always produced "black dust" even before conversion to storage. Early examination of the black dust showed Fe0, FeS2, Fe9S8, Fe3O4, S0. More recent examination of wellbore surface scale have shown $\mathrm{FeCO}$, $\mathrm{FeO}(\mathrm{OH})$, $\mathrm{Fe} 3(\mathrm{O}, \mathrm{OH}, \mathrm{Cl}), \mathrm{MgCl} 2, \mathrm{NaCl}$, and $\mathrm{SO}$.

3. Headers contain water condensate and have been know to contain scale.

4. Original gas content contain "mercaptan" of unspecified composition

5. There is no record of H2S, but there is a record of Carbonyl Sulfide (COS) in water solution.

6. Based on camera runs, build up of scale on tubulars and openhole sections can be on the order of $1 / 4$ inch thick and extends well above producing formation and casing shoe. Although there is no direct evidence of pitting in the tubulars, but this cannot be ruled out.

Based on these facts, we have developed the following working hypotheses.

Deposition of scale may occur primarily as a result of dehydration of water solutions. This can occur when dry gas is injected through residual pore water in the formation. This can also occur when gas in withdrawn if the reservoir gas is not already saturated with water.

Deposition of scale above the reservoir formation and in the casing occurs by entraining solution droplets in upward flow. The source of the elements in the scale is dominantly from the Oriskany, although some iron may come from tubulars and some sulfur may come from odorizers. The source of the water is the Oriskany. Although some water may come from formations between the casing shoe and the Oriskany, this is unlikely in well 1527 because of the short distance and the nature of these rocks.

Our objective for the remainder of the project is to generically characterize our findings. Specifically, we expect to:

1. Generically describe the geochemical environment in which siderite occurs.

2. Identify key geochemical reactions and components necessary to form siderite.

3. Identify practical methods to "interrupt" siderite formation in the field

4. Implement a field test to evaluate potential method(s) of siderite prevention.

5. Implement remedial treatments developed to remove siderite damage.

6. Evaluate the remedial treatments developed to remove siderite damage.

7. Document our results .

\section{Investigation of Damage Due to Non-Darcy Flow}

The investigation of wellbore damage due to non-darcy flow continues. To date we have reviewed non-darcy flow theory to identify which parameters significantly affect the nondarcy flow component of wellbore damage. We also performed a preliminary study to investigate the relative impact these parameters have on deliverability, and estimated the potential increases in deliverability that result when these parameters are altered. 
The implication of these relationships suggests that there are at least four practical ways we can reduce the pressure drop due to non-darcy flow. First, we could increase the effective permeability of the reservoir. Second, we could decrease the velocity of the fluids in the near-wellbore region by increasing the radius of the wellbore. Third, we could decrease the velocity of the fluids in the near-wellbore region by increasing the shots per foot in a cased hole completion. Fourth, in partially completed wells (i.e., wells that are not drilled completely through the reservoir), deepening the well through the entire reservoir would also reduce convergence of fluid flow in the near-wellbore region.

NODAL analysis sensitivity studies suggest that deliverability increases on the order of $50 \%$ are possible by successfully addressing the non-darcy flow issues discussed above. The exploration of practical methods of implementing field procedures to realize these theoretical improvements was started.

Technology transfer is underway. Numerous meetings with operators, consultants, and DOE have occurred, and several presentations have been made in the normal industry forums (Society of Petroleum Engineers, American Gas Association, Independent Oil \& Gas Association, etc.), outlining our intent and approach in an effort to secure additional participation in the project. 


\section{CONCLUSIONS}

The following preliminary conclusions can be drawn at this point:

1) Penn State has developed the laboratory testing protocol for the analysis of rotary sidewall cores collected from the study wells.

2) Construction of lab equipment for the analysis of rotary sidewall cores collected from the study wells has been completed.

3) The coring of National Fuel Gas Well 1527 in the Summit field has been completed.

4) Analysis of cores from Summit 1527 Well has been completed, and suggest the following:

a) The predominant organic precipitate present is siderite.

b) It appears that most of the damage occurs close to the wellbore.

c) Fractures are present in the reservoir.

d) There is very little damage due to plugging by organic materials.

e) The organic compounds that are present are mainly aliphatic hydrocarbons, long chain alkanes, and a very small amount of chlorinated alkanes.

f) A comparison of the cores from the old section of the wellbore with those from the newly drilled section of the wellbore suggests that:

i) Prior stimulations were reasonably effective at removing iron-related damage.

ii) Nonetheless, some mechanical damage remains, and it appears to be ironrelated damage.

iii) The color of the entire core differs, depending on whether it is from virgin formation or previously exposed formation. This may suggest that some damage occurs deeper in the formation. Notwithstanding this observation, the majority of he damage occurs within a few millimeters of the wellbore.

5) Our investigations suggest that there are practical ways to reduce the non-darcy skin damage in gas storage wells.

6) Implementation of the methods identified (to date) to reduce non-darcy flow in storage wells is expected to result in deliverability increases on the order of $50 \%$ in wells with damage caused by non-darcy flow. 


\section{REFERENCES}

1) American Gas Association: "Survey of Underground Gas Storage Facilities in the United States and Canada 1993" American Gas Association (1993).

2) Maurer Engineering Inc. and T. Joyce Associates, Inc: State-of-Technology Assessment and Evaluation of Gas Storage Well Productivity Enhancement Techniques, Gas Research Institute, (December 1993).

3) V.J. Yeager, M.E. Blauch, and F.R. Behenna: "Investigation of Storage Well Damage Mechanisms, Final Report (April 1995-August 1997)," Gas Research Institute (1997)

4) Frantz, J.H., Brown, K.G.: "Characterization of Conditions of Natural Gas Storage Reservoirs and Design and Demonstration of Remedial Techniques for Damage Mechanisms Found Therein Annual Technical Progress Report 1 October 2000 - 30 September, 2001", DOE (2001).

5) Erlougher, R.C., Jr.: Advances in Well Test Analysis, Society of Petroleum Engineers of AIME, Dallas, (1977).

6) McVay, D.A., Spivey, J.P.:"Optimizing Gas Storage Reservoir Performance," paper SPE 28693 presented at the 1994 Annual Technical Conference and Exhibition, New Orleans, LA, September 25-28, 1994.

7) Zuber, M. D., Deters Jr., J. C., and Lee, W. J.: "A Practical Approach for Analysis of a Pressure Transient Test From a Horizontal Well in a Gas Storage Reservoir," paper SPE 22675 presented at the 66th SPE Annual Technical Conference \& Exhibition, Dallas, TX, Oct. 6-9, 1991.

8) Holditch, S. A. and Morse, R. A.: "The Effects of Non-Darcy Flow on the Behavior of Hydraulically Fractured Gas Wells," J. Pet. Tech. (Oct. 1976).

9) Sawyer, W.K.: "The Practical Consequences of Non-Darcy Flow in Gas Storage Wells," presentation at the 1999 SPE Gas Storage/Stimulation Group Meeting, Morgantown, WV, June 17, 1999.

10) Yeager, V. J., Behenna, F. R.: "Investigation of Storage Well Damage Mechanisms - Final Report”, Halliburton Energy Resources, report, Gas Research Institute Contract No. 5095-270-3254, (1999).

11) Brown, K.G.: "Using Electronic Flow Measurement in Gas Storage Field Applications", presentation at the 1998 SPE Gas Storage Meeting, 1998.

12) Lee, W.J., Well Testing, Society of Petroleum Engineering of AIME, 1982, New York, NY. 
APPENDIX 1 


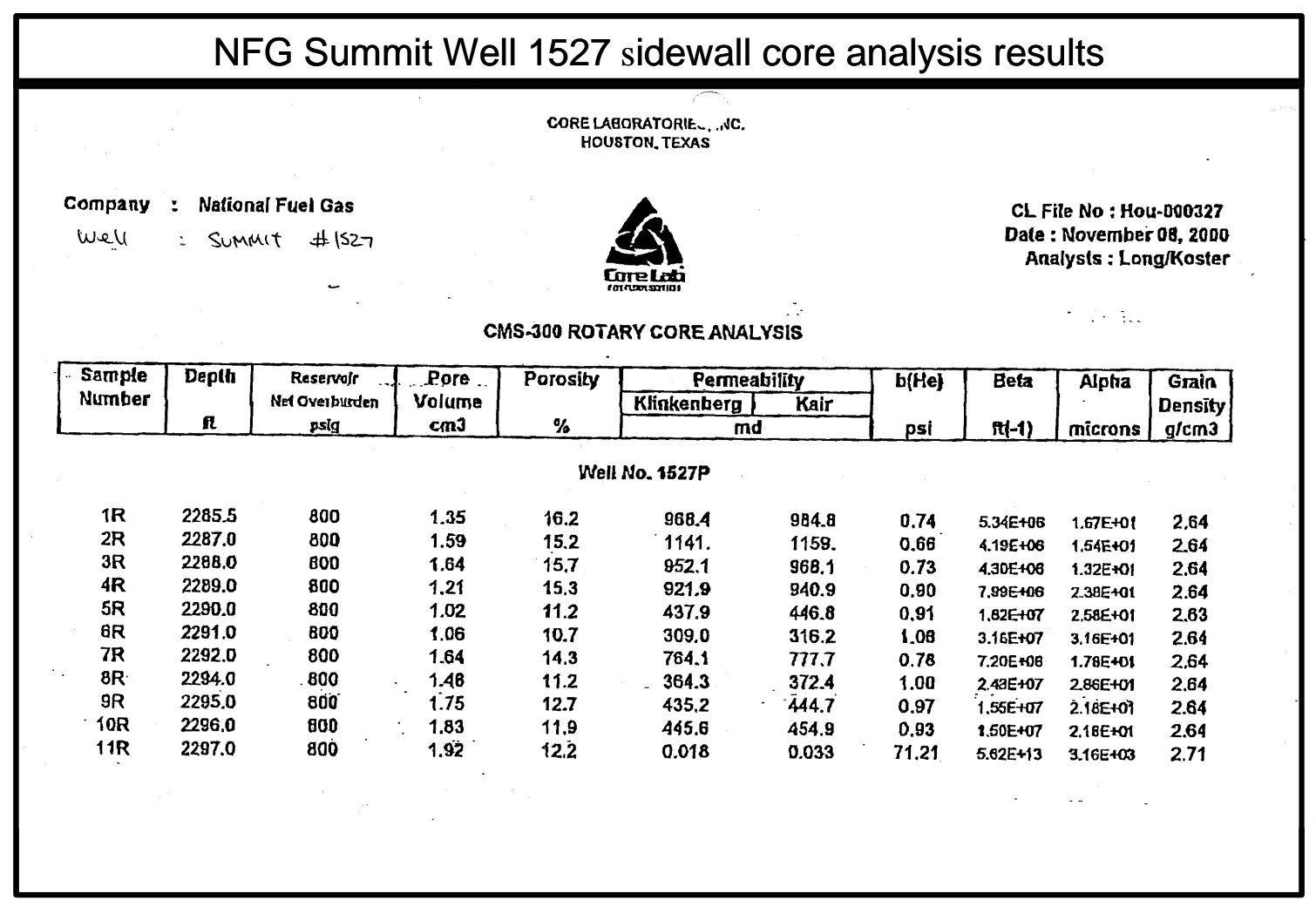

